\title{
Maternal thyroid function in multifetal pregnancies before and after fetal reduction
}

\author{
O Ogueh ${ }^{1}$, A P Hawkins ${ }^{1}$, A Abbas ${ }^{2}$, G D Carter ${ }^{3}$, \\ K H Nicolaides ${ }^{2}$ and $M$ R Johnson ${ }^{1}$ \\ ${ }^{1}$ Section of Obstetrics and Gynaecology, Imperial College School of Medicine, Chelsea and Westminster Hospital, 369 Fulham Road, London SW10 9NH, UK \\ ${ }^{2}$ The Harris Birthright Research Centre for Fetal Medicine, King's College Hospital Medical School, London SE5 8RX, UK \\ ${ }^{3}$ Department of Chemical Pathology, Imperial College School of Medicine, Charing Cross Hospital, Fulham Palace Road, London W6 8RF, UK \\ (Requests for offprints should be addressed to M R Johnson)
}

\begin{abstract}
The aim of the study was to investigate maternal thyroid function in pregnancy by monitoring the circulating concentrations of thyroid stimulating hormone (TSH), free thyroxine $\left(\mathrm{fT}_{4}\right)$ and human chorionic gonadotrophin (hCG) in multifetal pregnancies before and after embryo reduction. We studied two groups of women: group 1 comprised singleton $(n=12)$ and twin $(n=12)$ pregnancies achieved after superovulation and in vitro fertilisation and embryo transfer (IVF-ET), and group 2 were multifetal pregnancies $(n=39)$ undergoing selective fetal reduction to twin pregnancies. Blood samples were obtained initially at 10-12 weeks gestation (before fetal reduction) and then 4 and 8 weeks afterwards. Before fetal reduction, the circulating concentrations of $\mathrm{fT}_{4}$ in multifetal pregnancies were significantly greater than those in singleton or twin pregnancies (singleton, mean $16.49 \mathrm{pmol} / 1$ (interquartile range14.09-18.13 pmol/l); twins, 15.84 (15.36-
\end{abstract}

$16.95 \mathrm{pmol} / \mathrm{l})$; multifetal, $21 \cdot 08 \quad(16 \cdot 64-26 \cdot 29 \mathrm{pmol} / \mathrm{l})$; $P<0.005$ for singleton and twins), and in a multiple regression analysis, $\mathrm{fT}_{4}$ was significantly related to the number of fetuses $(F=23.739, P=0.0001)$, but not to hCG. After fetal reduction to twins, the circulating concentrations of $\mathrm{fT}_{4}$ in multifetal pregnancies decreased progressively towards those in control twin pregnancies, but remained significantly greater at both $4(P=0.003)$ and 8 weeks $(P=0 \cdot 050)$. This pattern of change in the concentrations of $\mathrm{fT}_{4}$ is similar to, but lags behind, that of hCG, which attains twin levels 4 weeks after fetal reduction. This may represent a delayed thyroid response to the decreasing concentrations of hCG, but the alternative is that the maternal thyroid function is controlled by a fetal factor in addition to hCG.

Journal of Endocrinology (2000) 164, 7-11

\section{Introduction}

Thyroid activity is increased during the first trimester of normal pregnancy, reflected by a decrease in the circulating concentrations of thyroid stimulating hormone (TSH) and an increase in the concentrations of free thyroxine $\left(\mathrm{fT}_{4}\right)$ and tri-iodothyronine $\left(\mathrm{fT}_{3}\right)$. The origin of the increased maternal thyroid function is almost certainly stimulation of the TSH receptor by human chorionic gonadotrophin (hCG) (Guillame et al. 1985, Yoshikawa et al. 1989, Glinoer et al. 1990, Ballabio et al. 1991). As the fetal thyroid is active only after 14 weeks gestation,it is suggested that the increased maternal thyroid activity ensures that normal neuronal development occurs in the fetus (Shepard 1975). The circulating concentrations of $\mathrm{TSH}, \mathrm{fT}_{4}$ and $\mathrm{fT}_{3}$ revert back to normal by the second trimester in most women, and remain within normal limits during the second and third trimesters (Harada et al. 1979).
The increase in thyroid activity in the first trimester is more profound in twin than in singleton pregnancy (Grun et al. 1997), probably because peak concentrations of hCG are greater and remain increased for longer in twin pregnancies (Grun et al. 1997). However, it has been suggested that factors other than hCG may be responsible for the pregnancy-associated increase in maternal thyroid function (Kennedy et al. 1992). The aim of the present study was to test the hypothesis that a factor other than hCG is responsible for the changes in maternal thyroid function. To achieve this, we measured the circulating concentrations of $\mathrm{TSH}, \mathrm{fT}_{4}$ and hCG before and after selective fetal reduction.

\section{Patients and Methods}

Two groups of women were examined. Group 1 comprised singleton $(n=12)$ and twin $(n=12)$ pregnancies 
Table 1 Circulating concentrations of $\mathrm{fT}_{4}, \mathrm{TSH}$ and hCG in sample 1, taken at 10-12 weeks gestation in all groups, and samples 2 and 3 taken at +4 and +8 weeks respectively. Data are median (interquartile range)

\begin{tabular}{|c|c|c|c|}
\hline & \multicolumn{3}{|c|}{ Circulating hormone concentration } \\
\hline & $\begin{array}{l}\text { Sample } 1 \\
\text { (pre-reduction) }\end{array}$ & $\begin{array}{l}\text { Sample } 2 \\
(+4 \text { weeks })\end{array}$ & $\begin{array}{l}\text { Sample } 3 \\
(+8 \text { weeks })\end{array}$ \\
\hline \multicolumn{4}{|l|}{$\begin{array}{l}\text { Hormone, and } \\
\text { pregnancy type } \\
\mathrm{fT}_{4}(\mathrm{pmol} / \mathrm{l})\end{array}$} \\
\hline Singleton & $\begin{array}{l}16 \cdot 49^{* *} \\
(14 \cdot 09-18 \cdot 13)\end{array}$ & $\begin{array}{l}14 \cdot 12^{*} \\
(12 \cdot 99-15 \cdot 92)\end{array}$ & $\begin{array}{l}13 \cdot 48 \\
(12 \cdot 75-14 \cdot 70)\end{array}$ \\
\hline Twin & $\begin{array}{l}15 \cdot 84^{* *} \\
(15 \cdot 36-16 \cdot 95)\end{array}$ & $\begin{array}{l}13 \cdot 04^{* *} \\
(12 \cdot 08-14 \cdot 95)\end{array}$ & $\begin{array}{l}12 \cdot 86 \\
(10 \cdot 58-13 \cdot 68)\end{array}$ \\
\hline Fetal reduction & $\begin{array}{l}21 \cdot 08 \\
(16 \cdot 64-26 \cdot 29)\end{array}$ & $\begin{array}{l}17 \cdot 60 \\
(14 \cdot 08-18 \cdot 70)\end{array}$ & $\begin{array}{l}13 \cdot 97 \\
(12 \cdot 57-15 \cdot 40)\end{array}$ \\
\hline \multicolumn{4}{|l|}{ TSH (mU/l) } \\
\hline Singleton & $\begin{array}{l}1 \cdot 077^{* *} \\
(0 \cdot 42-2 \cdot 06)\end{array}$ & $\begin{array}{l}1 \cdot 45^{\star \star} \\
(1 \cdot 05-3 \cdot 27)\end{array}$ & $\begin{array}{l}1 \cdot 07 \\
(0 \cdot 93-2 \cdot 36)\end{array}$ \\
\hline Twin & $\begin{array}{l}0 \cdot 70 \\
(0 \cdot 20-1 \cdot 21)\end{array}$ & $\begin{array}{l}1 \cdot 275^{*} \\
(0 \cdot 87-1.96)\end{array}$ & $\begin{array}{l}0 \cdot 813 \\
(0 \cdot 25-1 \cdot 29)\end{array}$ \\
\hline Fetal reduction & $\begin{array}{l}0 \cdot 113 \\
(0 \cdot 013-0 \cdot 89)\end{array}$ & $\begin{array}{l}0 \cdot 382 \\
(0 \cdot 01-1 \cdot 21)\end{array}$ & $\begin{array}{l}1 \cdot 145 \\
(0 \cdot 63-1 \cdot 90)\end{array}$ \\
\hline \multicolumn{4}{|l|}{ hCG (IU/I) } \\
\hline Singleton & $\begin{array}{l}90 \cdot 6^{* *} \\
(73 \cdot 69-105 \cdot 65)\end{array}$ & $\begin{array}{l}41 \cdot 69^{* *} \\
(26 \cdot 48-61 \cdot 6)\end{array}$ & $\begin{array}{l}16 \cdot 6^{* *} \\
(14 \cdot 11-37 \cdot 76)\end{array}$ \\
\hline Twin & $\begin{array}{l}138 \cdot 6 \\
(113 \cdot 4-186 \cdot 1)\end{array}$ & $\begin{array}{l}83 \cdot 3^{*} \\
(29 \cdot 5-90 \cdot 2)\end{array}$ & $\begin{array}{l}57 \cdot 6 \\
(31 \cdot 8-97 \cdot 9)\end{array}$ \\
\hline Fetal reduction & $\begin{array}{l}201 \cdot 9 \\
(134 \cdot 1-232 \cdot 7)\end{array}$ & $\begin{array}{l}123 \cdot 3 \\
(75 \cdot 6-192 \cdot 7)\end{array}$ & $\begin{array}{l}53 \cdot 9 \\
(36 \cdot 5-79 \cdot 2)\end{array}$ \\
\hline
\end{tabular}

${ }^{*} P<0 \cdot 05,{ }^{* *} P<0 \cdot 01$ compared with multifetal values.

achieved after superovulation and in vitro fertilisation and embryo transfer (IVF-ET), recruited from the Assisted Conception Unit, King's College Hospital, and group 2 were multifetal pregnancies (three to eight fetuses, $n=39$ : three fetuses $n=22$, four fetuses $n=6$, five fetuses $n=7$, six fetuses $n=3$ and eight fetuses $n=1$ ) undergoing selective fetal reduction to twin pregnancies, recruited from The Harris Birthright Research Centre for Fetal Medicine, King's College Hospital. The multifetal pregnancies occurred after a variety of assisted reproduction techniques that included ovulation induction, superovulation and intra-uterine insemination, and superovulation and IVF. They were referred from a variety of units. Fetal reduction to twins was carried out by ultrasound-guided transabdominal injection of potassium chloride into the fetal heart. Ultrasound demonstrated complete reabsorption of the feto-placental units 8-12 weeks after reduction. In group 1 , blood samples were obtained initially at 10-12 weeks gestation and then 4 and 8 weeks afterwards. In group 2, blood was obtained before reduction at 10-12 weeks gestation and then at 4 and 8 weeks after reduction. The Ethics Committee of King's College Hospital approved the study and the women gave informed consent to participate.

TSH and $\mathrm{fT}_{4}$ were measured using the Elecsys electrochemiluminescence immunoassay analyser (Roche
Diagnostic Ltd, Lewes, UK). Inter-assay precision (coefficient of variation) was as follows: $\mathrm{fT}_{4}, 4.7 \%(8.8 \mathrm{pmol} / \mathrm{l})$ and $5 \cdot 2 \%(34.5 \mathrm{pmol} / \mathrm{l})$; TSH, $6 \cdot 9 \%(0 \cdot 32 \mathrm{mU} / \mathrm{l}), 5 \cdot 3 \%$ $(7 \cdot 8 \mathrm{mU} / \mathrm{l})$ and $5 \cdot 1 \%(26 \cdot 0 \mathrm{mU} / \mathrm{l})$. hCG was measured by non-competitive fluoroimmunoassay (Pharmacia Wallac, Milton Keynes, Bucks, UK.). The variation (intra- and inter-assay) for these assays over the period of the study was less than $10 \%$.

The data were not normally distributed, and nonparametric tests (Mann-Whitney $U$ ) were used to analyse the data. Simple and multiple regression analysis were used to investigate the associations between analytes and fetal number.

\section{Results}

There was no significant difference in the circulating concentrations of $\mathrm{fT}_{4}$ between singleton and twin pregnancies $(P=0.95$ at $10-12$ weeks, $P=0.40$ at $14-16$ weeks, and $P=0.21$ at $18-20$ weeks). However, before fetal reduction, the $\mathrm{fT}_{4}$ concentrations were greater in multifetal pregnancies when compared with singleton or twin pregnancies $(P<0 \cdot 005)$ (Table 1$)$. After fetal reduction to twins, the circulating concentrations of $\mathrm{fT}_{4}$ in multifetal pregnancies decreased progressively, but remained significantly different from those in twin 


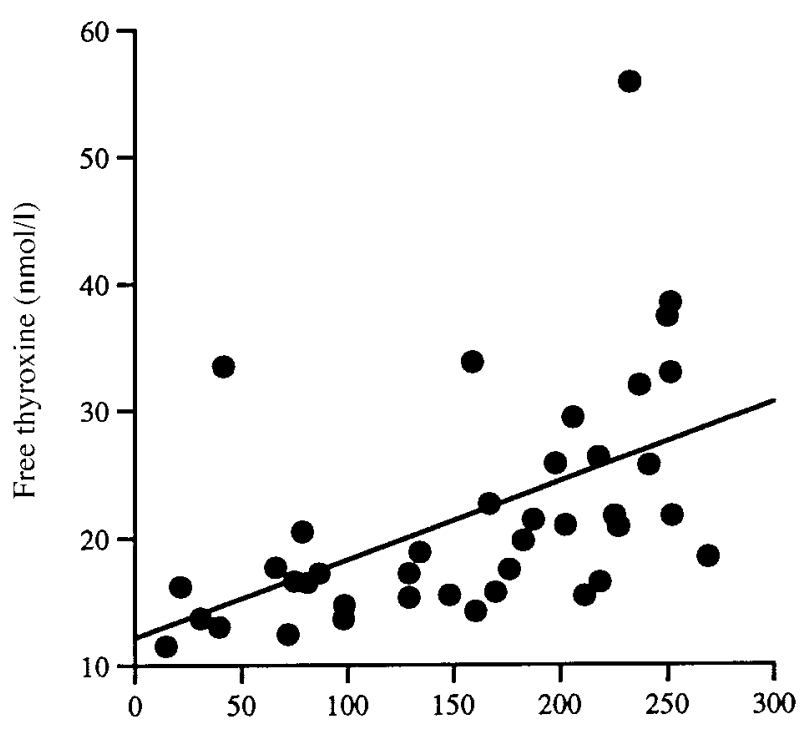

Human chorionic gonadotrophin $(\mathrm{IU} / \mathrm{l} \times 1000)$

Figure 1 Relationship between the circulating concentrations of $\mathrm{fT}_{4}$ and human chorionic gonadotrophin $(r=+0 \cdot 52, P=0 \cdot 0006)$.

pregnancies at 8 weeks $(P=0.003$ and $P=0.0502$ at 4 and 8 weeks after reduction respectively) (Table 1 ).

There was no significant difference in the circulating concentrations of TSH between singleton and twin pregnancies $(P=0.20$ at $10-12$ weeks, $P=0 \cdot 41$ at $14-16$ weeks, and $P=0 \cdot 14$ at $18-20$ weeks). However, before fetal reduction, the TSH concentrations were significantly lower in multifetal pregnancies compared with singleton, but not twin, pregnancies $(P=0.005$ and $P=0.23$ respectively) (Table 1). After fetal reduction to twins, the circulating concentrations of TSH in multifetal pregnancies increased to twin pregnancy values by 8 weeks $(P=0.025$ and $P=0.19$ at 4 and 8 weeks after reduction) (Table 1).

Before fetal reduction, there was a positive association between the circulating concentrations of $\mathrm{fT}_{4}$ and both hCG $(r=0.52, P=0006$; Fig. 1$)$ and fetal number $(r=0.63$ and $P<0.0001$; Fig. 2 ); and a negative association with TSH concentrations $(r=-0.52, P=0 \cdot 0001$; Fig. 3$)$. Thus, for a given hCG concentration, $\mathrm{fT}_{4}$ concentration is proportionately greater when there are multiple fetuses. However, using multiple regression analysis, including all the above variables, $\mathrm{fT}_{4}$ was significantly related to the number of fetuses (a positive relationship) and TSH (a negative relationship, Overall $F=23.739$; for number of fetuses Partial $F=18.199$ and $P=0 \cdot 0001$; for TSH Partial $F=10.629$ and $P=0.0019)$, but not to hCG.

\section{Discussion}

It has been reported that hCG has a thyroid-stimulating effect in vitro (Davies \& Platzer 1986). The thyrotrophic

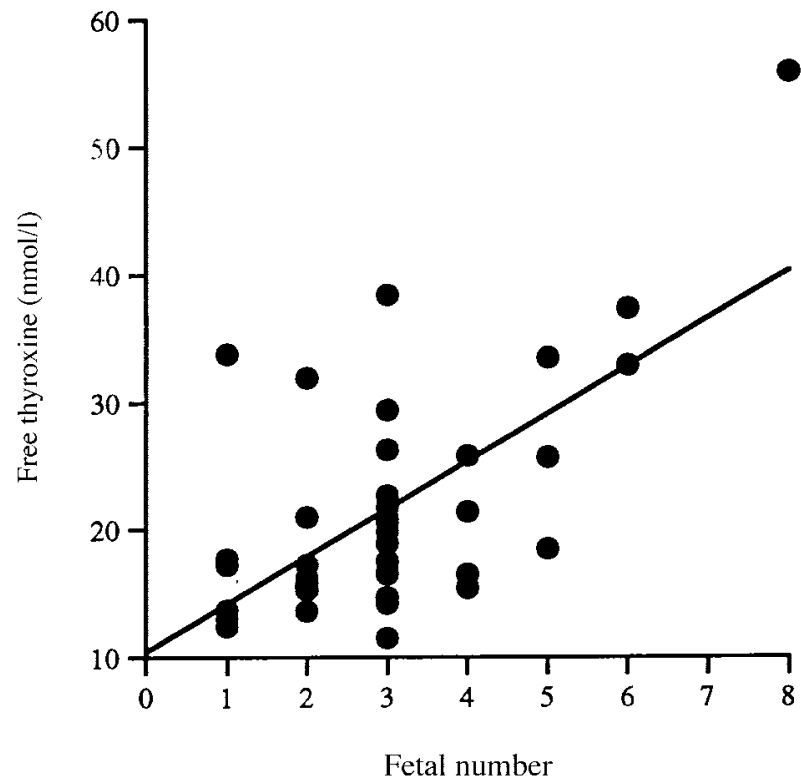

Figure 2 Relationship between the circulating concentrations of $\mathrm{fT}_{4}$ and fetal number $(r=+0 \cdot 63, P<0 \cdot 0001)$. Singleton $(n=12)$, twin $(n=12)$ and multifetal pregnancies $(n=39)$.

activity of hCG is believed to be due to the homology between the TSH and hCG molecular structures, and receptors with only a $15 \%$ sequence difference between them (Nisula et al. 1974, Yoshikawa et al. 1989). However, thyroid stimulation by hCG is reported to be weak and to be effective only at high concentrations of hCG

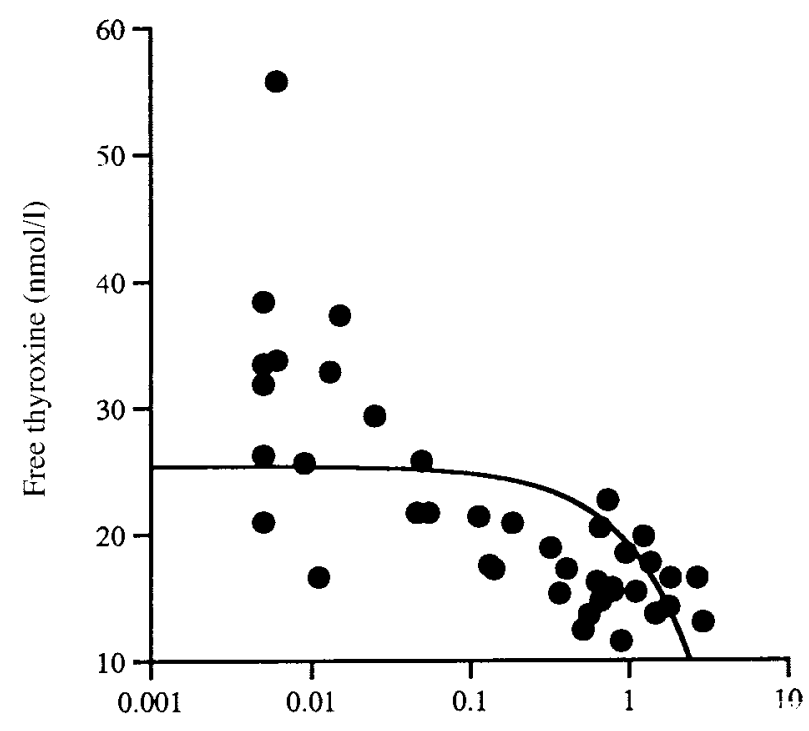

Log thyroid stimulating hormone (IU/I)

Figure 3 Relationship between the circulating concentrations of $\mathrm{fT}_{4}$ and log thyroid stimulating hormone concentration $(r=-0 \cdot 52$, $P=0 \cdot 0001$. 
(Guillaume et al. 1985). These data would explain why overt hyperthyroidism is seen only in some women and then only in the first trimester, when hCG concentrations are greatest, and the occurrence of clinical and biochemical hyperthyroidism in women with hCG-producing tumours such as hydatidiform mole and choriocarcinoma (Miyai et al. 1976). Indeed, the spectrum of increasing thyroid activity correlates with the severity of disease and the concentration of hCG, suggesting a causal relationship (Kenimer et al. 1975). At the cellular level, hCG is believed to increase intracellular release of cAMP in the thyroid, which leads to a degranulation response, and the secretion of thyroxine. In vitro data have not fully supported this view, as only a minimal increase in secretion occurs in response to hCG (Kraiem et al. 1994). However, the conflict may well be due to the isoform of hCG used, as its effect at the TSH receptor is determined by its glycosylation and can range from stimulation to inhibition (Hoermann et al. 1994, Poertl et al. 1995). Such data suggest that hCG is probably the only factor involved in the alteration of maternal thyroid function in early pregnancy, but the possibility remains that other factors are also involved.

After fetal reduction, the concentrations of hCG decrease to those of control twin pregnancies by 4 weeks, suggesting that fetal reduction causes placental death and therefore production of hCG by the remaining pregnancies at a rate similar to that in control twins (Johnson et al. 1994). In contrast, after fetal reduction, the maternal concentrations of alpha fetoprotein $(\alpha-\mathrm{FP})$ increase, and remain increased for at least 8 weeks (Abbas et al. 1994). This pattern is probably due to the gradual breakdown of fetal tissue, the release of $\alpha$-FP into amniotic fluid, and its subsequent absorption into the maternal circulation (Abbas et al. 1994). We found that multifetal pregnancy reduction was associated with a decrease in the circulating concentrations of $\mathrm{fT}_{4}$ to those of the control group by 8 weeks, but at 4 weeks the concentrations of $\mathrm{fT}_{4}$ were still significantly greater. The relative delay in the decrease in $\mathrm{fT}_{4}$ compared with hCG may reflect a delay in the thyroid response to decreasing hCG concentrations. However, as $\mathrm{fT}_{4}$ was related to the number of fetuses but not to hCG concentrations in the multiple regression analysis, it is possible that a fetal factor is also involved in the alteration of maternal thyroid function in pregnancy. If this were so, it would explain the similarity in the pattern of $\mathrm{fT}_{4}$ decline to that of $\alpha$-FP described above. A further possibility is that the form of hCG, which has thyroid stimulating-properties, may be cleared at a slower rate and so continues to stimulate thyroid activity for longer than anticipated by the total circulating concentrations of hCG. However, to account for the relationship between $\mathrm{fT}_{4}$ concentrations and fetal number, concentrations of this form of hCG would have to be more closely related to fetal number than are total hCG concentrations.
We have shown that, in multiple pregnancy, thyroid activity increases with fetal number. This is consistent with the greater circulating concentrations of $\mathrm{fT}_{4}$ and lesser circulating concentrations of TSH in twin, compared with singleton, pregnancies (the measurements between 8-15 weeks were pooled; Grun et al. 1997). However, the difference in TSH was not statistically significant and that of the $\mathrm{fT}_{4}$ was significant at the $P=0.046$ level (Grun et al. 1997). With twin pregnancies, we have demonstrated a similar pattern for TSH, but not $\mathrm{fT}_{4}$. The lack of difference between singleton and twin pregnancies in our study may be because our samples were collected at 10-12 weeks gestation (rather than at 8 weeks onwards), when the altered concentrations of TSH and $\mathrm{fT}_{4}$ may have reverted to normal (Harada et al. 1979). In contrast, the alteration in thyroid physiology is more profound in multifetal pregnancies and still apparent at 10-12 weeks.

As we do not have pre-pregnancy thyroid function tests, it is possible that the women with multifetal pregnancies had greater concentrations of $\mathrm{fT}_{4}$, that this promoted implantation of multiple fetuses, and that this is the origin of the observed differences in maternal thyroid function. However, we would not have expected to see a decline in maternal $\mathrm{fT}_{4}$ concentrations after reduction, had this been the case. Similarly, it seems unlikely that maternal thyroid function is materially altered by the treatment used to achieve pregnancy, but this cannot be excluded.

In conclusion, there is profound alteration in thyroid physiology in multifetal pregnancies, which may be due to a combination of hCG and a fetal factor. Further studies are needed to elucidate whether such a fetal factor exists and, if so, what it is.

\section{References}

Abbas A, Johnson M, Bersinger N \& Nicolaides K 1994 Maternal alpha-fetoprotein levels in multiple pregnancies. British Journal of Obstetrics and Gynaecology 101 156-158.

Ballabio M, Poshychinda M \& Ekins RP 1991 Pregnancy-induced changes in thyroid function: role of human chorionic gonadotropin as putative regulator of maternal thyroid. Journal of Clinical Endocrinology and Metabolism 73 824-831.

Davies TF \& Platzer M 1986 HCG-induced TSH receptor activation and growth acceleration in FRTL-5 thyroid cells. Endocrinology 118 2149-2151.

Glinoer D, de Nayer P, Bourdoux P, Lemone M, Robyn C, van Steirteghem A, Kinthaert J \& Lejeune B 1990 Regulation of maternal thyroid during pregnancy. Journal of Clinical Endocrinology and Metabolism 71 276-287.

Grun JP, Meuris S, De Nayer P \& Glinoer D 1997 The thyrotrophic role of human chorionic gonadotrophin (hCG) in the early stages of twin (versus single) pregnancies. Clinical Endocrinology 46 719-725.

Guillaume J, Schussler GC \& Goldman J 1985 Components of the total serum thyroid hormone concentrations during pregnancy: high free thyroxine and blunted thyrotropin (TSH) response to TSHreleasing hormone in the first trimester. Journal of Clinical Endocrinology and Metabolism 60 678-684.

Harada A, Hershman JM, Reed AW, Braunstein GD, Dignam WJ, Derzko C, Friedman S, Jewelewicz R \& Pekary AE 1979 
Comparison of thyroid stimulators and thyroid hormone concentrations in the sera of pregnant women. Journal of Clinical Endocrinology and Metabolism 48 793-797.

Hoermann R, Broecker M, Grossmann M, Mann K \& Derwahl M 1994 Interaction of human chorionic gonadotropin (hCG) and asialo-hCG with recombinant human thyrotropin receptor. Journal of Clinical Endocrinology and Metabolism 78 933-938.

Johnson MR, Abbas A \& Nicolaides KH 1994 Maternal plasma levels of human chorionic gonadotrophin, oestradiol and progesterone in multifetal pregnancies before and after fetal reduction. Journal of Endocrinology 143 309-312.

Kenimer JG, Hershman JM \& Higgins HP 1975 The thyrotropin in hydatidiform moles is human chorionic gonadotropin. Journal of Clinical Endocrinology and Metabolism 40 482-491.

Kennedy RL, Darne J, Cohn M, Price A, Davies R, Blumsohn A \& Griffiths H 1992 Human chorionic gonadotropin may not be responsible for thyroid-stimulating activity in normal pregnancy serum. Journal of Clinical Endocrinology and Metabolism 74 260-265.

Kraiem Z, Sadeh O, Blithe DL \& Nisula BC 1994 Human chorionic gonadotropin stimulates thyroid hormone secretion, iodide uptake, organification, and adenosine $3^{\prime}, 5^{\prime}$-monophosphate formation in cultured human thyrocytes. Journal of Clinical Endocrinology and Metabolism 79 595-599.
Miyai K, Tanizawa O, Yamamoto T, Azukizawa M \& Kawai Y 1976 Pituitary-thyroid function in trophoblastic disease. Journal of Clinical Endocrinology and Metabolism 42 254-259.

Nisula BC, Morgan FJ \& Canfield RE 1974 Evidence that chorionic gonadotropin has intrinsic thyrotropic activity. Biochemical and Biophysical Research Communication 59 86-91.

Poertl S, Liss L, Mann K \& Hoermann R 1995 Crude urinary human chorionic gonadotropin contains variant forms of HCG with low sialic acid content that exhibit an increased thyrotropic activity in $\mathrm{CHO}$ cells expressing the human TSH receptor. Experimental and Clinical Endocrinology and Diabetes 103 168-174.

Shepard TH 1975 Development of the thyroid gland. In Endocrine and Genetic Diseases of Childhood and Adolescence, edn 2. Ed LI Gardner. Philadelphia: WB Saunders.

Yoshikawa N, Nishikawa M, Horimoto M, Yoshimura M, Sawaragi S, Horikoshi Y, Sawaragi I \& Inada M 1989 Thyroid-stimulating activity in sera of normal pregnant women. Journal of Clinical Endocrinology and Metabolism 69 891-895.

Received 4 May 1999

Accepted 12 August 1999 